\title{
Comparison of PZT and FBG sensing technologies for debonding detection on reinforced concrete beams strengthened with external CFRP strips subjected to bending loads
}

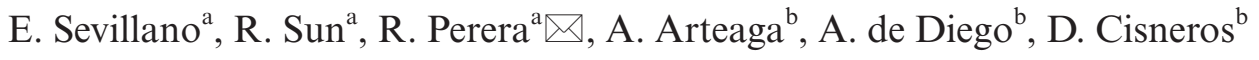 \\ a. Department of Structural Mechanics. Technical University of Madrid (Madrid, Spain) \\ b. Eduardo Torroja Institute for Construction Science, IETcc-CSIC (Madrid, Spain) \\ $\triangle$ perera@etsii.upm.es
}

Received 7 July 2015 Accepted 3 December 2015 Available on line 18 April 2016

\begin{abstract}
The development of monitoring technologies particularly suitable to be used with novel CFRP strengthening techniques has gained great attention in recent years. However, in spite of the high performance of these advanced composite materials in the strengthening and repairing of structures in service, they are usually associated with brittle and sudden failure mainly caused by debonding phenomena, originated either at the CFRP-plate end or at the intermediate areas in the vicinity of flexural cracks in the RC beam. Thus, it is highly recommended for these structures to be monitored in order to ensure their integrity while in service. Specifically, the feasibility of smart sensing technologies such as Fiber Bragg Grating (FBG) sensors and piezoimpedance transducers (PZT) has been studied. To the knowledge of the authors, none serious study has been carried out until now concerned to the topic of damage detection due to debonding in rehabilitated structures with CFRP composites.
\end{abstract}

KEYWORDS: Composite; Fibre reinforcement; Concrete; Polymer; Mechanical properties

Citation/Citar como: Sevillano, E.; Sun, R.; Perera, R.; Arteaga, A.; de Diego, A.; Cisneros, D. (2016) Comparison of PZT and FBG sensing technologies for debonding detection on reinforced concrete beams strengthened with external CFRP strips subjected to bending loads. Mater. Construcc. 66 [322], e088 http://dx.doi.org/10.3989/ mc.2016.05415

RESUMEN: Comparación de sensores PZT y FBG para la detección de despegues en vigas de hormigón armado reforzadas externamente con bandas de CFRP y sometidas a cargas de flexión. El desarrollo de tecnologías de monitorización aplicables junto con las novedosas técnicas de refuerzo basadas en materiales CFRP ha recibido una atención creciente los últimos años. Sin embargo, a pesar del alto rendimiento de estos avanzados materiales compuestos en la reparación y refuerzo de estructuras en servicio, están habitualmente asociados a fallos frágiles y repentinos causados principalmente por fenómenos de despegue, originados bien en los extremos del refuerzo, bien en áreas intermedias en las proximidades de grietas de flexión existentes en la viga. Por tanto, es altamente recomendable monitorizar estas soluciones estructurales de cara a garantizar su integridad en servicio. Específicamente, se ha estudiado la viabilidad de sensores inteligentes tales como los sensores Fiber Bragg Grating (FBG) o los transductores piezoeléctricos (PZT). Hasta donde los autores saben, no se han realizado estudios serios hasta la fecha abordando la detección de daño debido al despegue en estructuras reforzadas con compuestos CFRP.

Palabras Clave: Composite; Refuerzo de fibras; Hormigón; Polímero; Propiedades mecánicas

Copyright: (C) 2016 CSIC. This is an open-access article distributed under the terms of the Creative Commons Attribution-Non Commercial (by-nc) Spain 3.0 License. 


\section{LIST OF ACRONYMS}

$$
\begin{array}{ll}
\text { SHM } & - \text { Structural Health Monitoring. } \\
\text { CFRP } & - \text { Carbon Fiber Reinforced Polymer. } \\
\text { RC } & - \text { Reinforced Concrete. } \\
\text { FBG } & - \text { Fiber Bragg Grating. } \\
\text { PZT } & - \text { Lead Zirconate Titanate (piezoelec- } \\
& \text { tric ceramic material). } \\
\text { EMI } & - \text { Electro-Mechanical Impedance. } \\
\text { RMSD }- \text { Root Mean Square Deviation }
\end{array}
$$

\section{INTRODUCTION}

Aerospace, civil and mechanical infrastructures are continuously exposed to deterioration and functional deficiencies for which, regardless of the root cause (aging, accidental damage, weathering of the materials, poor engineering, etc.), a solution is needed in terms of monitoring and maintenance. In order to mitigate this deterioration and efficiently manage maintenance work on civil structures, it has become necessary to develop reliable damage detection strategies, referred to (1) in the infrastructure-engineering field as Structural Health Monitoring. Furthermore, in order to contribute to the cost reduction of that rehabilitation, a lot of research has been put into the use of Carbon Fiber Reinforced Polymers (CFRP) composites for repairing and strengthening structures in service. Advanced composite materials are increasingly used, particularly for strengthening applications of reinforced concrete (RC) structures (2-4), due to their many advantages over the traditional techniques: high strength-to-weight ratio, high modulus of elasticity, improved durability, resistance to corrosion, and ease of handling. Particularly interesting is the CFRP reinforcement of the flexural members, since these are the most developed applications among civil infrastructures (5-8).

Unfortunately, strengthening with CFRP is often associated with brittle and sudden failure caused mainly by some form of debonding of the CFRP from the concrete (9-17). In this regard, considerable research activity has been centered lately on the development of 'smart structures' (18), although little of this 'smart' technology has been actually applied to monitor retrofitted structural systems. The first step in this development is to incorporate a level of structural sensing capability, embedding some of the latest smart sensor networks so that these new solutions can also serve to assess the integrity of strengthened structures. This can be achieved, for example, through the use of strain measurements taken at multiple locations throughout the structure. Within the smart structures community there has been increasing recognition of the potential of fiber-optic sensors $(19,20)$, particularly Fiber Bragg grating (FBG) sensors, for multi-point structural strain monitoring. These sensors have the capability of mapping the strains along the optic fiber, as they are able to measure those strains locally with high resolution and accuracy. Another promising approach to be explored within the concept of 'smart structures' or 'intelligent material systems' is the use of piezoelectric materials (piezo-impedance transducers, PZT) (21), which have the particularity that they can serve as both sensors and actuators, thus providing driving signals as well as sensing (22), for systems that do not contain natural excitations or for diagnostic algorithms that require a known, well-controlled excitation. Furthermore, these sensors are able to measure at much higher frequencies than those used in global structural methods, which greatly improves the sensitivity to minor damage.

Both kinds of smart sensors are widely recognized as promising technologies in the SHM field, but few efforts have been made so far to incorporate these smart solutions within the SHM procedures that allow the assessment of the health condition of civil infrastructures externally strengthened with advanced composite materials. For that reason, both smart sensor technologies are used in this work in order to test their performance for debonding detection on Reinforced Concrete (RC) structures externally strengthened with CFRP composite materials. The purpose of this paper is, thus, to track damage evolution on experimental beams so that, from the accumulation of damage indications in certain regions of the structure (due mainly to flexural cracks), debonding appearance could be predicted by means of these smart sensors before the beam reaches a critical condition while in service, which could originate a catastrophic failure. Two identical RC beams with the same steel reinforcement and also the same external CFRP strengthening have been used during the experimental campaign carried out for this paper. Furthermore, a different loading sequence has been applied to each beam in order to achieve a more comprehensive experimental test.

\section{OPTIC FIBER TECHNOLOGY: USAGE OF FBG SENSORS}

Among all fiber optic solutions for sensing technologies, Fiber Bragg Gratings (FBGs) are the most widely applied ones given the number of commercial systems available and their high performance besides other significant advantages compared to other strain measurement techniques, such as their immunity to electromagnetic interference and power fluctuation along the optical path, high precision, durability, low power consumption, absolute strain sensing capability, ease of multiplexing and compatibility with being embedded in a range of structural materials $(23,24)$, which makes them particularly suitable for being used for monitoring the structural systems studied in this work. Furthermore, due to these advantages FBG sensors have been increasingly used in many real applications (24-27). 
These fibers consist of a very small inner core that has a periodic variation of its diffraction index with a periodic lambda $(\lambda)$, which is generally achieved by exposing the core of photosensitive optical fibers to light from an ultraviolet laser (23). The sensor reflects a portion of the incoming light with a particular wavelength known as Bragg wavelength, while the rest of the light keeps traveling with its properties unaltered through the optic fiber. Thanks to the modulation of its core, Bragg wavelength can be affected by external environment changes, such as temperature, vibration or strains, thus generating a shift of the reflected Bragg wavelength. As the gratings can be written at different initial wavelengths, they can be identified by their spectral location, and correlated to physical locations along the fiber. This gives the sensor system the capability to 'map' the strain along the fiber, and offers a new and very powerful sensing capability for structural analysis (28). For example, when adhered to the surface of the host structure (or embedded in the structure) it is possible to obtain the record of strains of the structure subjected to any external load, which is highly useful in order to develop an SHM system in real time. Furthermore, the wavelength-encoded nature of the output also provides the basis for the multiplexing of several gratings along a single optical fiber.

In this work, several FBG sensors have been used to monitor the strain variations in reinforced concrete beams externally strengthened with CFRP strips (see Section 5) during different loading programs, as detailed in Section 4. The strains for each experiment were calculated by using the following expression [1], given by the manufacturer of the FBGs:

$$
\varepsilon=\frac{\left(\Delta \lambda / \lambda_{0}\right) \cdot 10^{6}}{F_{G}}
$$

where $\varepsilon$ is the micro-strain, $\Delta \lambda$ is the Bragg wavelength shift, $\lambda_{0}$ the original Bragg wavelength and $F_{G}$ a factor also given by the manufacturer for each FBG sensor.

\section{ELECTROMECHANICAL IMPEDANCE METHOD}

Lead-zirconate-titanate (PZT) materials have become a very widespread technology for sensing and monitoring solutions in many engineering fields, civil engineering among them, due to their light weight and variety of shapes and sizes (29-32). More particularly, these smart materials are especially suitable for Structural Health Monitoring applications by means of the so-called ElectroMechanical Impedance method (EMI). The principle behind the impedance-based structural health monitoring approach is that any damage present in the structure under study leads to a change in its mechanical properties, the mechanical impedance among them. Since the patch is directly attached to or even embedded in the host structure, that change in the mechanical impedance of the structure also means a modification of the electromechanical impedance of the PZT patch, which can be directly measured by an impedance analyzer. The coupled relationship between electrical and mechanical impedance was firstly introduced by Liang et al (33) as follows [2]:

$$
\begin{aligned}
Y(\omega)= & \frac{I_{0}}{V_{i}}=G(\omega)+j B(\omega)=\varepsilon_{33}^{-T} \\
& -\frac{Z_{3}(\omega)}{Z_{3}(\omega)+Z_{3}(\omega)} d_{3 x}^{2} \hat{Y}_{x x}^{E}
\end{aligned}
$$

where $Y(\omega)$ is the electrical admittance (inverse of impedance), $v_{i}$ is the input voltage to the PZT actuator; $I_{0}$ the output current from the PZT; $\varepsilon_{33}^{-T}, d_{3 x}^{2}$ and $\hat{Y}_{x x}^{E}$ are the geometry constant, complex dielectric constant, piezoelectric coupling constant and complex Young's modulus of the PZT in a state without stresses, respectively; $Z_{s}(\omega)$ and $Z_{a}(\omega)$ are the impedances of the structure and the PZT actuator, respectively. As has been proved (Park et al (34)), the real part is less sensitive to ambient temperature change, compared to the imaginary part. Because of this, a real part of the impedance is used for the EMI method.

Through the application of the EMI method, the integrity of the structure can be assessed by observing the changes experienced by the electromechanical impedance of the structural system between two different stages. In order to obtain a quantitative measure of the damage level present in the structure, it is necessary to use statistical tools that allow one to define different scalar damage metrics that lead to that quantitative assessment of the health condition. In that sense, the root mean square deviation (RMSD) is the most commonly used indicator for the impedance method $(35,36)$, which can be computed as follows [3]:

$\operatorname{RMSD}(\%)=\sqrt{\frac{\sum_{i=1}^{n}\left[\operatorname{Re}\left(Z_{0}\left(\omega_{i}\right)\right)-\operatorname{Re}\left(Z_{1}\left(\omega_{i}\right)\right)\right]^{2}}{\sum_{i=1}^{n}\left[\left(\operatorname{Re}\left(\omega_{i}\right)\right)\right]^{2}}} \cdot 100[3]$

where $Z_{0}\left(\omega_{i}\right)$ is the impedance of the PZT measured at a previous stage, which might agree with the healthy condition of the structure, $Z_{1}\left(\omega_{i}\right)$ is the corresponding value at a subsequent stage, which might agree with a post-damage stage, at the $i$ th frequency point; $n$ is the number of frequency points. For the RMSD index, the larger the difference between the baseline reading and the subsequent reading, the greater the value of the index denoting changes of structural dynamic properties which can be due to damage. 
Finally, Yang et al (35) carried out an study with PZT transducers to detect damage artificially introduced on a $2 \mathrm{~m} \times 1.5 \mathrm{~m} \times 1.5 \mathrm{~m}$ concrete mass. The approach was based on dividing the wide frequency range (which in this work will cover from $10 \mathrm{kHz}$ up to $100 \mathrm{kHz}$ ) into sub-frequency intervals of the same length, calculating their respective RMSD values and correlating them with different sensing regions in the host structure. In that way, damage closer to a PZT would affect the higher sub-frequency intervals more significantly, meanwhile the lower ones would be related to further damages. A similar approach has also been considered in this work.

\section{TEST DESCRIPTION}

Two RC beams with the same steel reinforcement and also the same external CFRP strengthening were used during the experimental campaign carried out in this work at the Eduardo Torroja Institute (Madrid-Spain), in order not only to study the behavior of these reinforced concrete beams, but also to test the performance and adequacy of the selected smart sensors for the particular monitoring application evaluated in this paper. The mechanical properties of the tested specimens are presented in Table 1. The geometric dimensions and the reinforcement layout in the transversal sections, which were common for both beams, are illustrated in Figure 1, and details about the sensors used are given in Figure 2. For a better understanding, Figure 3 shows the basic FBG strain sensing principles. The procedure for the specimens preparation is properly illustrated in Figure 4, while the overall experimental set-up is shown in Figure 5.

In each test program performed, the corresponding strengthened beam was subjected to a series of increasing quasi-static load tests (detailed in Table 2) with the purpose of gradually generating cracks into the specimen. Each damage state is also specified in this table for each health condition of each beam after the corresponding loading step.

During the application of each loading step, the microstrains were constantly measured by using identical os3200 Non-metallic Optical Strain Gages supplied by Micron Optics, as indicated in Figure 1. In order to measure the microstrains

TABLE 1. Material properties

\begin{tabular}{lccccc}
\hline Property & Concrete 1 & Concrete 2 & Steel & Adhesive & CFRP \\
\hline$E(\mathrm{GPa})$ & 25.90 & 24.86 & 210 & - & 150 \\
$G(\mathrm{MPa})$ & - & - & - & 4300 & - \\
$f_{c}(\mathrm{MPa})$ & 27.30 & 24.64 & 510 & - & - \\
$\rho\left(\mathrm{kg} / \mathrm{m}^{3}\right)$ & 2350 & 2350 & 7850 & - & - \\
$v$ & 0.2 & 0.2 & 0.3 & - & 0.35 \\
$e(\mathrm{~mm})$ & - & - & - & 3.45 & 1.4 \\
\hline
\end{tabular}

at each sensor, the dynamic Optical Sensing Interrogator sm130 from Micron Optics was used for data acquisition, in combination with the sm041 Channel Multiplexer from the same firm, so that all the FBG sensors could be interrogated at once. For beam number 1, the results from sensor number 6 were not considered since they were illogical and not consistent, so we concluded that there could have been adherence failures with this sensor during the tests. In the case of beam number 2, results for sensor 2 were not included since that sensor broke during the first load of the test program.

After each quasi-static test, the impedance was then measured by using, in both specimens, eleven identical P-876 Dura Act Patch Transducers of $0.5 \mathrm{~mm}$ thickness supplied by Piceramics, which were externally bonded with an epoxy adhesive along the CFRP strip with a constant spacing ratio of $12 \mathrm{~cm}$ (Figure 1). To measure the impedances at each sensor, the Precision Impedance Analyzer 4294A from Agilent Technologies was used to apply a sinusoidal sweep voltage with a 1 volt amplitude to the PZT sensors over a frequency range of between $10 \mathrm{kHz}$ and $100 \mathrm{kHz}$. The Agilent Multiplexer 3499B enabled the possibility of switching between sensors so that the measurement process could be optimized. Initially, the impedance measurements were captured before loading each beam so that stages D10 (first beam) and D20 (second beam) were respectively obtained. Before measuring the impedances corresponding to the next step, the beam was previously unloaded after each loading stage. In the case of beam number 1 , results for sensors 5 and 11 were not included since both sensors broke before starting the tests.

\section{EXPERIMENTAL RESULTS AND DISCUSSION}

Specimen number 1 failed when the last loading step reached $\mathrm{F}=69.5 \mathrm{kN}$ (139 $\mathrm{kN}$ in total), while specimen number 2 failed with $\mathrm{F}=66.5 \mathrm{kN}(133 \mathrm{kN}$ in total). In both cases, the dominant failure mode was the one expected for these kinds of strengthened beams: by intermediate crack debonding of the external CFRP reinforcement.

\subsection{FBG Response to Strains}

\section{RC-Beam number 1}

As detailed in Section 4, an optical sensing interrogator was used to collect measurements from all sensors at once, with the support of a channel multiplexer, monitoring the structure not only during the load application, but also before and after, so the evolution of the strains in the external surface of the CFRP strip would be obtained during the entire loading procedure at 


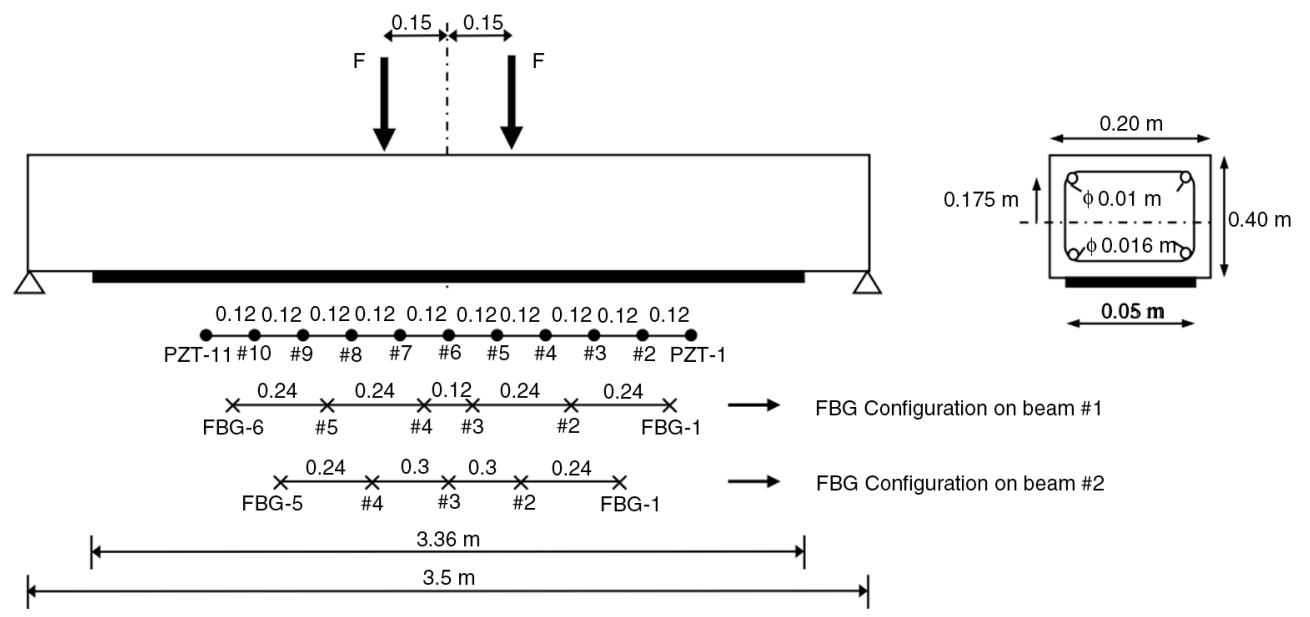

FIgURE 1. Geometry, loading scheme and sensor location map for the RC beams.

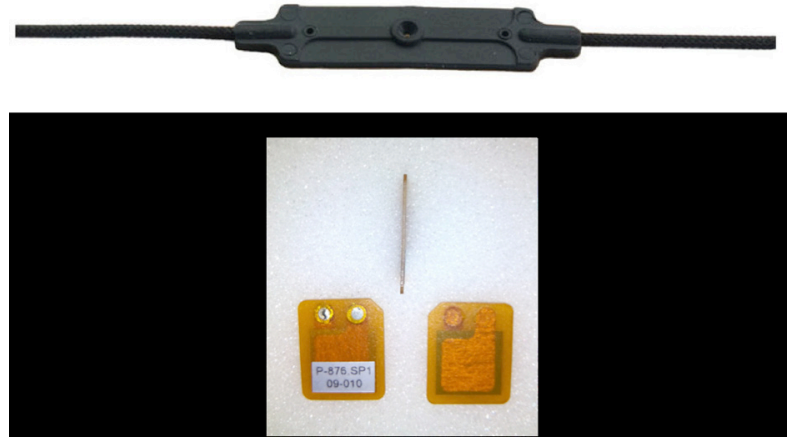

FIgure 2. FBG sensors (top) and PZT sensors (bottom).

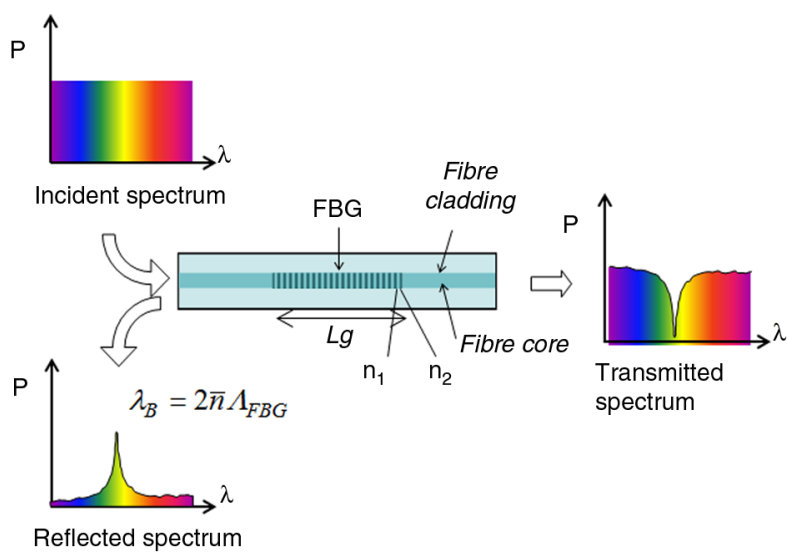

FIgURE 3. Basic FBG strain sensing principle.

different locations along the beam. These results are shown in Figure 6.

In Figure 6, sensor number 5 shows clearly that the strain increments after the fourth loading step are noticeably higher than the rest. However, although this fact might lead one to conclude with certainty that there is incipient debonding in the vicinity of this sensor (several flexural cracks can be observed in this region - Figure 7), here there is one limitation, which is that there is no way to distinguish between just a simple concentration of flexural cracks and the real origin of debonding damage. Actually, the origin of the debonding could be estimated after the whole test program, to be 18 centimeters away from sensor number 5 , which shows the sensitivity of these sensors to the appearance and propagation of cracks. Sensor number 4, whose results clearly differ from the rest (green line in Figure 6), is located closer to the damage, but its strain increments are not significant at all (it is expectable that higher strain values on the strip lead to earlier debonding appearance due to the higher concentration of stresses in the area), which clearly lead to a misleading conclusion about the damage: in comparison to sensor number 5 , it seems that the results from sensor number 4 indicate that there is no presence of damage in its vicinity, which is totally false given the damage distribution shown in Figure 7. Nevertheless, given the difference between these results and those from the rest of the sensors, it is reasonable to discard sensor number 4 from this analysis due to a possible anomaly in the measurements. Finally, it is important to remark that sensors numbers 2 and 3 almost obtain the same results, which makes sense since each of them turned out to be located close to a debonding region, according to the observations made after the whole loading test program in Figure 8. However in practice, sensor number 2 was a bit closer to its corresponding disbond, which could explain why, at the end of the strain curve, the strain increment is exponentially higher for sensor 2 than for sensor 3.

\section{RC-Beam number 2}

Analogue strain measurements were taken for beam \#2, whose results are shown in Figure 9, where 
(a)

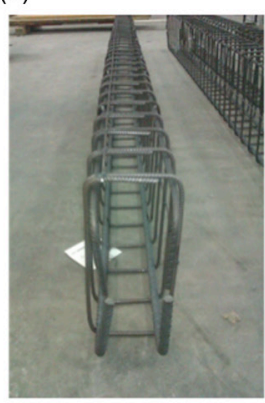

(e)

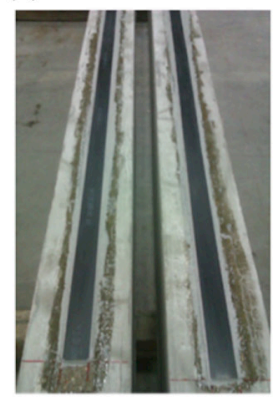

(b)

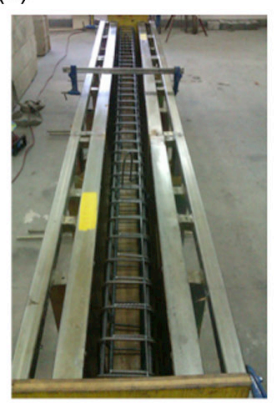

(f)

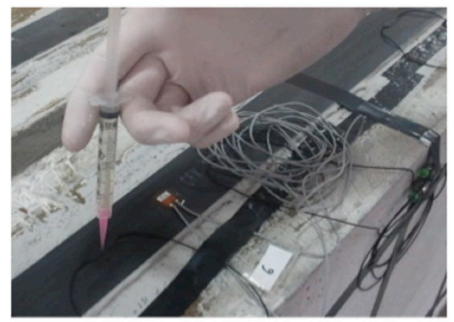

(c)

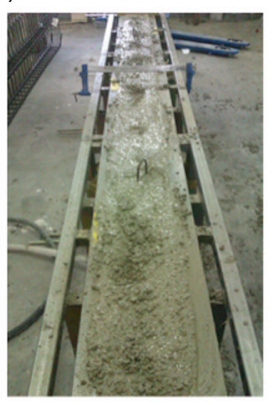

(d)

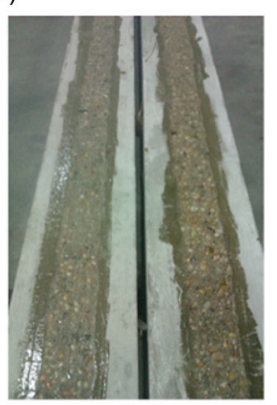

(g)

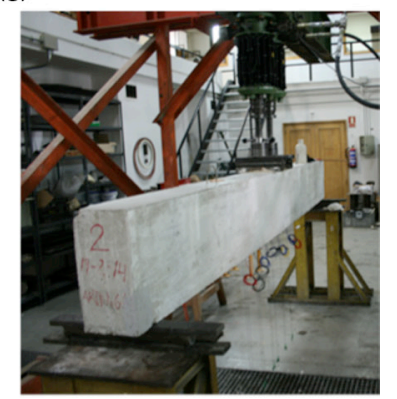

FIGURE 4. Specimen preparation's procedure: (a) tied stirrups and longitudinal reinforcement; (b) steel reinforcement inside the formwork; (c) concrete casting; (d) beams' bottom surfaces after sand blasting operations; (e) CFRP reinforcement; (f) instrumentation of the beams; (g) simple supports and loads preparation

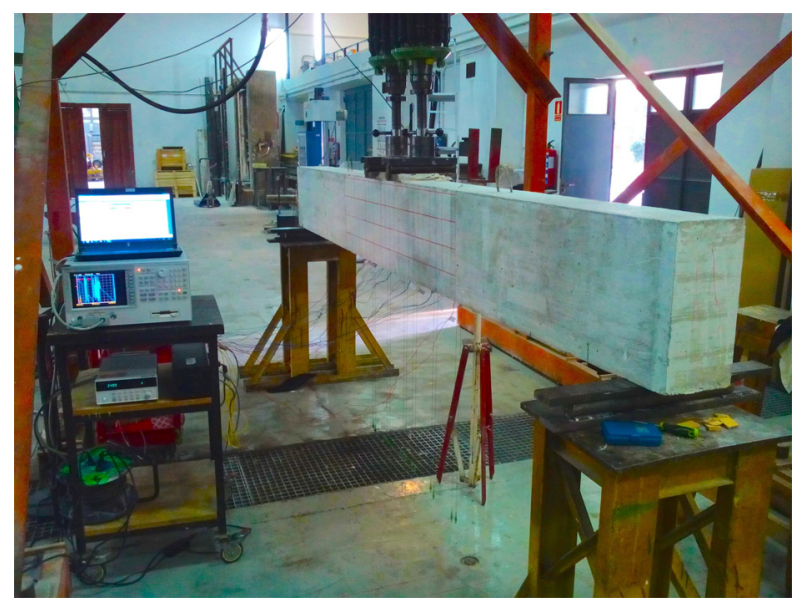

FIGURE 5. Experimental setup for the RC beams externally strengthened with CFRP

TABLE 2. Static loading test points for each beam (see Figure 1) and damage stage correspondence

\begin{tabular}{cccccccc}
\hline Beam & Load F (kN) & Damage & Beam & Load F (kN) & Damage \\
\hline \multirow{6}{*}{1} & 1. & 13 & D11 & & 1. & 26 & D21 \\
& 2. & 20 & D12 & & 2. & 32.5 & D22 \\
& 3. & 32.5 & D13 & & 3. & 40 & D23 \\
& 4. & 50 & D14 & 2 & 4. & 50 & D24 \\
& 5. & 69.5 & D15 & & 5. & 56.5 & D25 \\
& & & & & 6. & 60 & D26 \\
& & & & & 7. & 66.5 & D27 \\
\hline
\end{tabular}

all data collected from the FBGs in all loading steps are depicted.

From this Figure it is easy to see how FBG number 3 is the one collecting the highest strain increments among all the sensors deployed along the beam. This induces one to consider that this sensor is in the vicinity of an area with a high concentration of cracks, which may lead to debonding failure, and due to the remarkable difference between the strain increments measured by this sensor and the rest, it actually seems reasonable to conclude that the concentration of flexural cracks in this location incite the debonding appearance (Figures 10 and 11 would support this conclusion). However, according to the observations made with the previous beam, this is just a qualitative assessment and it is not enough for an accurate damage prediction. The rest of the sensors in Figure 9 show almost the same progression through time, clearly lower than that followed by FBG number 3 when increasing the loads, so no further conclusions could be obtained by a direct inspection of the diagram except the fact that in all those positions the damage by debonding is, initially, expected to be lower.

\subsection{Electromechanical Impedance Measurements}

RC-Beam number 1

As mentioned earlier, an impedance analyzer applying a sinusoidal-sweep voltage of 1 volt was 


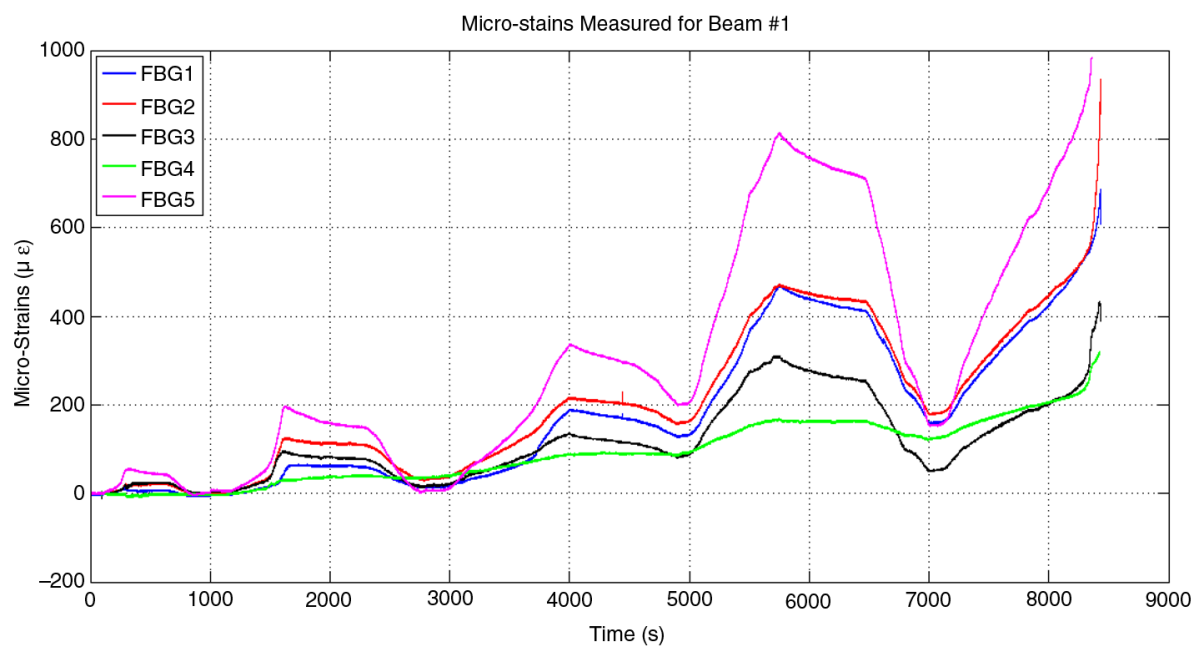

FIgURE 6. Microstrains measured for RC-Beam \#1.

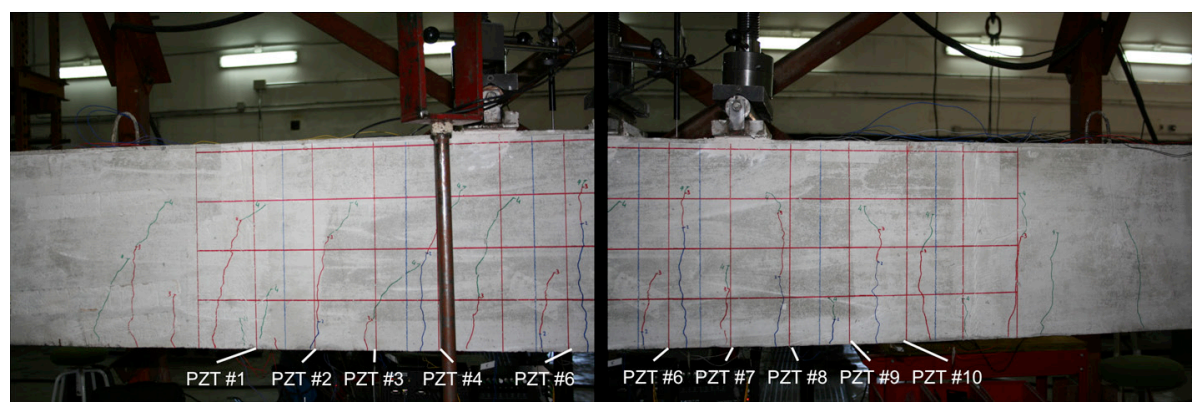

FIGURE 7. Cracking map of the RC-Beam \#1 after the last loading stage.

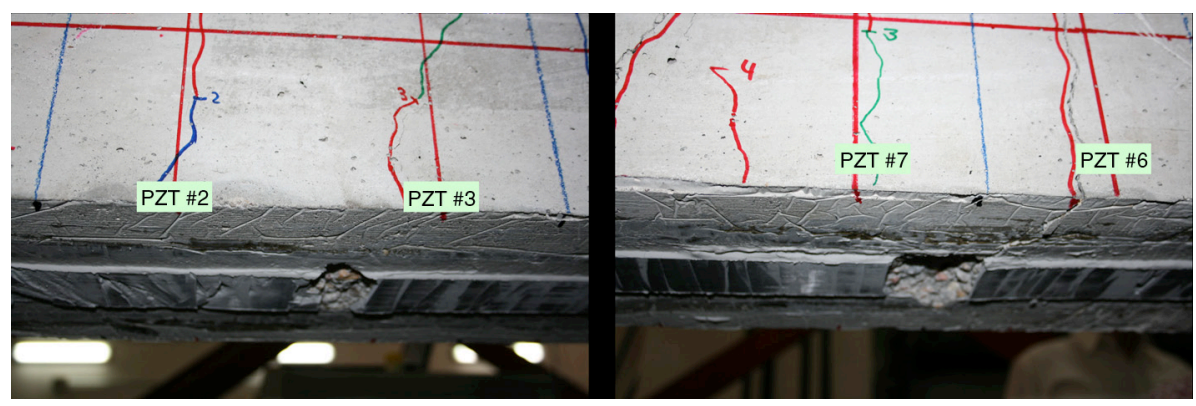

FIGURE 8. Damages with concrete cover separation between sensors 2 and 3 (left) and sensors 6 and 7 (right) for the RC-Beam \#1.

used to capture the electromechanical impedance signatures of the structure, monitoring it from $10 \mathrm{kHz}$ to $100 \mathrm{kHz}$ after each static load test (Table 2). Initially, the impedance curves were obtained for all sensors in order to define, prior to the loading sequence, stage D10, i.e., the baseline of the beam in terms of impedances. These results are shown in Figure 12.
The differences encountered in Figure 12 between all the curves are due to the slightly different amount of adhesive used to bond each sensor to the CFRP surface, as well as their being caused by the soldering process applied to each PZT patch. The cracking map for this specimen once the whole test program had been applied is shown in Figure 7. At a first glance, it is easy to deduce that the mechanical capabilities of 


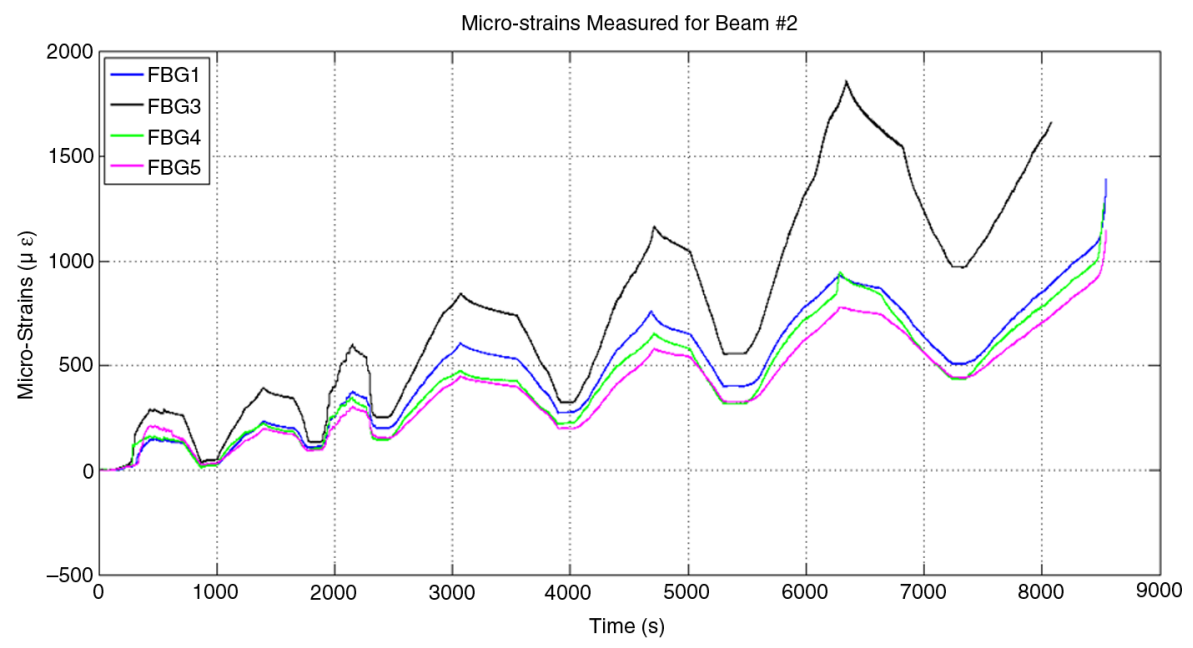

Figure 9. Microstrains measured for RC-Beam \#2.

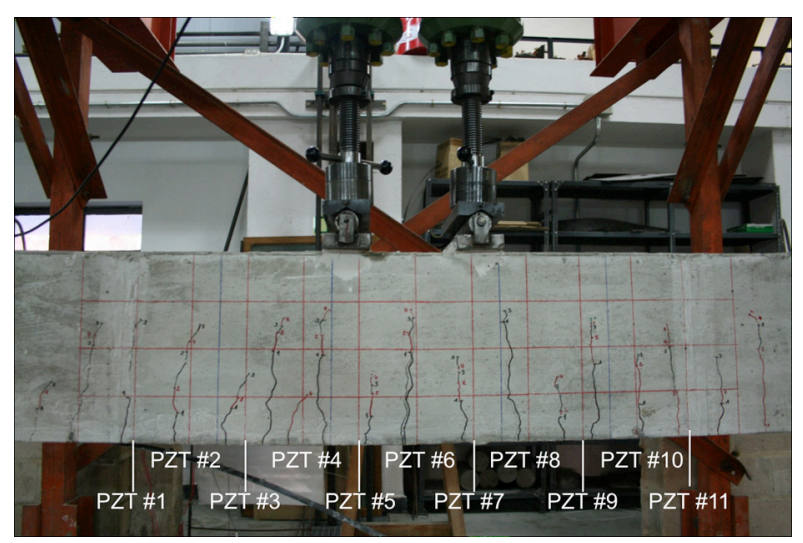

Figure 10. Cracking map of the RC-Beam \#2 after the last loading stage.

the structure have been significantly reduced, given the crack distribution along the beam, which should result in a noticeable impact on the electromechanical impedance signatures, not only for the presence of the cracks themselves, but also for the deterioration of the adhesion between the concrete surface and the CFRP strip, which might have been compromised and so, it is considered as damage. Thus, the impedance curves are expected to have different shapes from one loading step to the following one, but not all of them in the same degree of change. In order to demonstrate how the debonding can be easily prevented in early steps from the study of the evolution of these impedances, the stage after the application of the first load is going to be analyzed as an example, in contrast to the undamaged status. No cracks were observed in the beam in this step (the load was lower than the critical cracking load), at least under human eye inspection. However, some of the sensors reacted (while others did not) indicating that damage had actually been caused, either in the inner part of the concrete or in the interphase between the concrete and the CFRP. This situation is illustrated in Figure 13, where the impedance signatures for PZT \#1 and PZT \#3 are compared between Stage D10 and Stage D11. While sensor 1 does not seem to show any reaction to the new health condition, sensor number 3 clearly shows a modification of the impedance curve, specially around the highest frequency ranges, which suggests not only the presence of damage in the beam, but also and more important, that this damage is close to sensor 3 (35).

In order to obtain a quantitative evaluation of the damage from the impedance signatures, the statistical indicator RMSD is now used, as explained in Section 3. Since RMSD is computed for one stage by using the previous stage as baseline, only the appearance of new damage with respect to the baseline stage should be reflected in the RMSD value. Following with the example of the analysis of damage stage D11, Figure 14 shows the RMSD values for $\mathrm{D} 11$, where the $\mathrm{X}$-axis indicates each one of the considered frequency ranges (number 1 corresponding to the $10-20 \mathrm{kHz}$ range, and so on), and the RMSD values are indicated as a percentage.

It is clear, from the figure, that sensor 3 is the most affected by the damage, even when no visual cracks were detected during and after the loading process. This indicates that, around the position of sensor 3, there is a potential debonding location. By evaluating the RMSD values for the rest of the sensors, it is easy to see how sensor 2 is the second more affected by the presence of damage, while sensor 4 is practically not affected at all. From this fact, it can be concluded that there is a potential damage by debonding emerging between sensors 2 and 3 , which actually came to be confirmed at the 


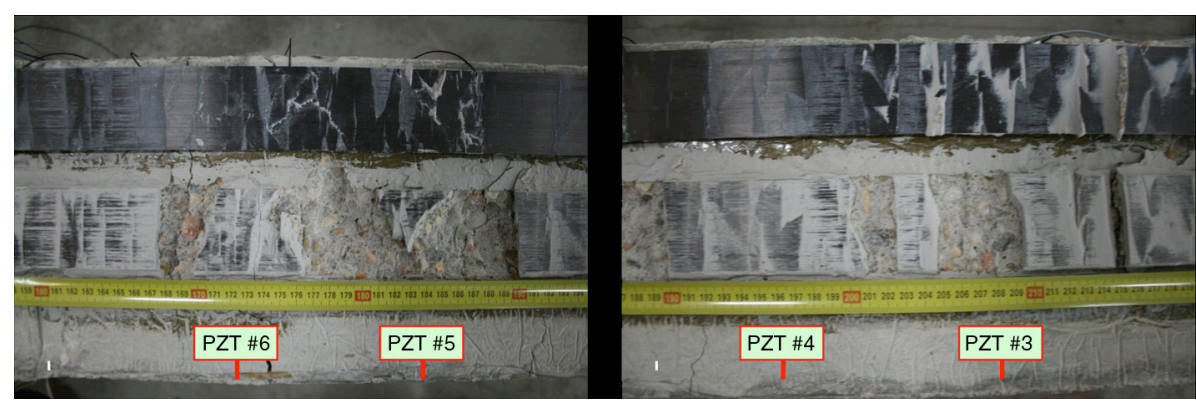

FIGURE 11. Damages with concrete cover separation between sensors 5 and 6 (left) and sensors 3 and 4 (right) for the RC-Beam \#2.

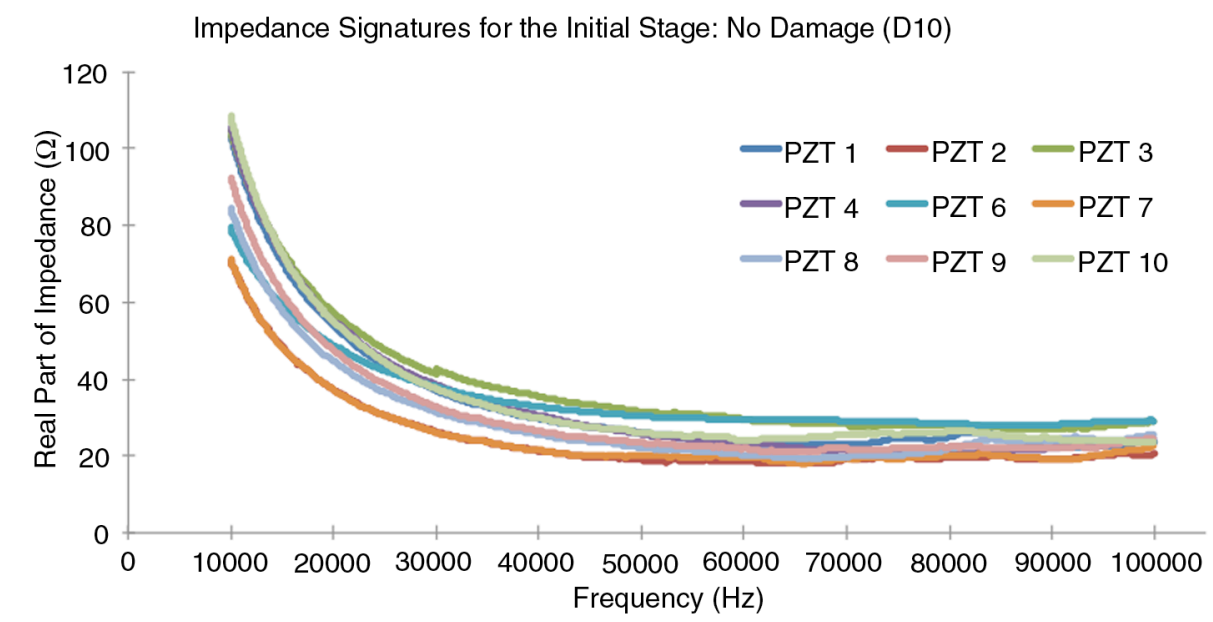

FIGURE 12. Impedance signatures for the initial stage (D10) of RC-Beam \#1.
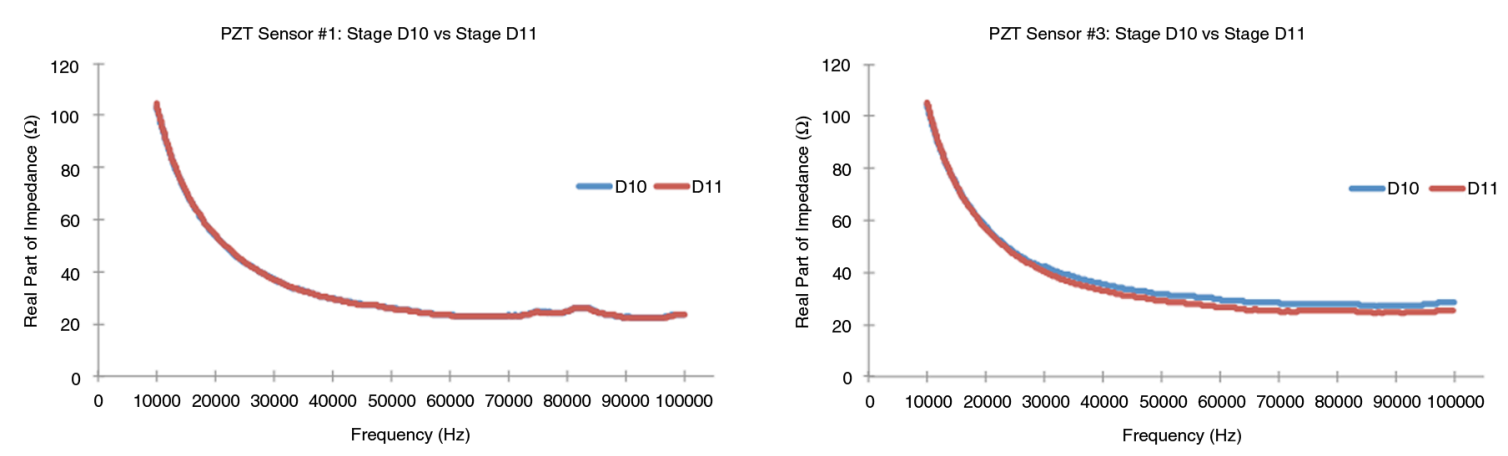

FIGURE 13. Stage D10 vs Stage D11 comparison for sensors \#1 and \#3.

end of the test program as shown in Figure 8. On the other hand, in Figure 14 it is also confirmed that, at that point of the test program, no damage seems to have been originated around the position of sensor 1, where no debonding was detected, as advanced in the analysis of Figure 13.
After increasing the loads, as could be expected, all sensors experienced an increment of their respective RMSD values in every damage case, but only the sensing regions close to sensors numbers 2,7 and 9 could be considered as potentially affected by debonding failure, according to the 


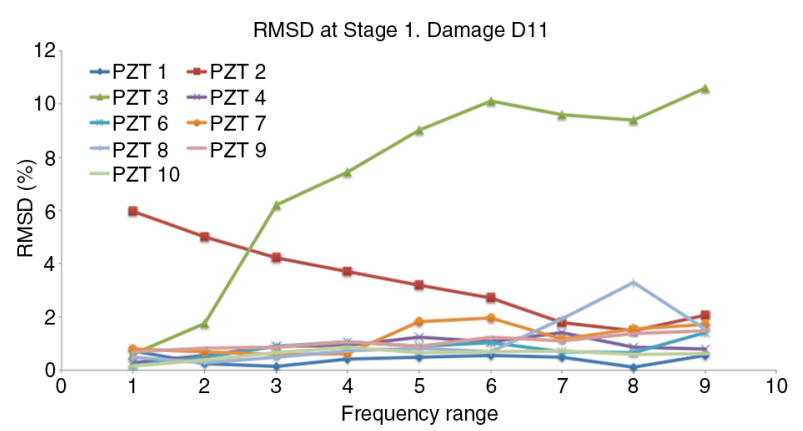

FIGURE 14. RMSD values for the comparison between Stage D10 and Stage D11.

specially high RMSD values found for them after some loading steps.

In the case of sensor number 7, the RMSD after D12 was $4.32 \%$ at $50-60 \mathrm{kHz}$, and it kept above $2.5 \%$ for the high frequency ranges until the failure of the beam, which supposes a noticeable and constant weakness of the interface between FRP and concrete in this region. A similar behavior is found for sensor number 2 after D12 $(4.5 \%$ at $70-80 \mathrm{kHz})$ and after D13 $(4.47 \%$ at $60-70 \mathrm{kHz})$, and again with values around $2.5 \%$ for the high frequency ranges until the failure of the beam. Therefore, these two regions are likely to suffer debonding effects, as it is actually well demonstrated in Figure 8. Sensor number 9, however, shows some high RMSD values after D13 (4.74\% at $70-80 \mathrm{kHz})$ and after D14 (4.57\% at $60-70 \mathrm{kHz})$, but the rest of RMSD values were quite low for all the rest of the cases, so we consider that the interfase cannot be considered for debonding appearance.

\section{$\underline{\text { RC-Beam number } 2}$}

In the same way as was done with the other specimen, this beam was subjected to the corresponding static loads specified in Table 2. Once again, the impedance measurements were captured before loading each beam so that stage D20 (baseline of the beam) could be defined. These results are shown in Figure 15.

Differences encountered in Figure 15 between all the curves are due to the same reasons detailed in the previous example, all of them related to the mechanical set-up of the experiment. Furthermore, the values of the impedances also differ slightly to the previous ones, since the compressive cylinder strength resulted to be lower for this specimen.

In Figure 10, the cracking map after the whole loading procedure is shown on one of the beam's sides. As occurred with the previous specimen, the complex damage condition of the specimen suggests that its mechanical properties, as well as the adhesion between concrete and CFRP, have been significantly affected.

As in the previous example, once again, the RMSD value is used in order to assess the integrity

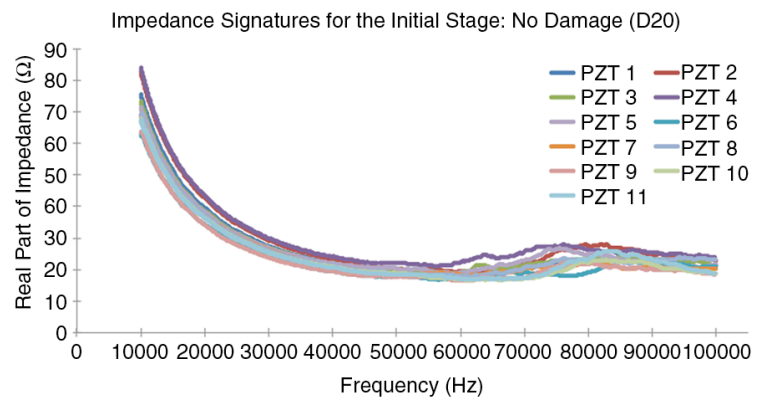

FIGURE 15. Impedance signatures for the initial stage (D20) of RC-Beam \#2.

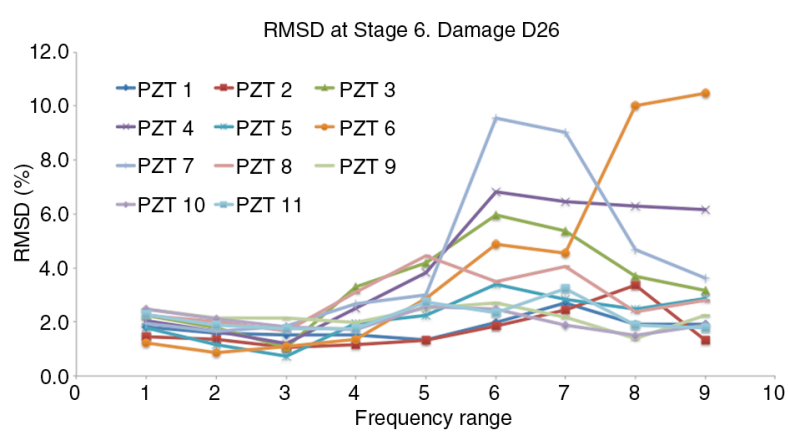

FIGURE 16. RMSD values for the comparison between Stage D25 and Stage D26.

of the structure. Figure 16 shows the RMSD values for each one of the frequency ranges.

Damage stage D26, which is actually very close to the failure condition of the beam, is analyzed this time in Figure 16. As can be appreciated in this figure, the sensors presenting higher RMSD values are sensor $4(6.28 \%$ at $80-90 \mathrm{kHz}$ and $6.1 \%$ at $90-100 \mathrm{kHz})$, sensor $6(10 \%$ at $80-90 \mathrm{kHz}$ and $10.47 \%$ at $90-100$ $\mathrm{kHz})$, sensor $3(5.97 \%$ at $60-70 \mathrm{kHz}$ and $5.36 \%$ at $70-80 \mathrm{kHz})$, and sensor $7(9.55 \%$ at $60-70 \mathrm{kHz}$ and $9 \%$ at $70-80 \mathrm{kHz}$ ). Although the indication of sensor \#5 is not remarkable at all in this graphic, it collected a number of important RMSD high values in previous stages, a fact that makes that the interface between the FRP and the concrete becomes really weak in the entire region between sensor 4 and sensor 7, being more likely the debonding appearance.

Although sensor number 7 did not show such remarkable RMSD values in previous stages, the ones collected here at lower frequency ranges than the rest of the sensors (sensor 6 in particular), made us think that this sensor also detected the weakness of the interface around sensor 6 as a further damage at this stage. Finally, it is also clear that the region between sensors \#3 and \#4 is also likely to be debonded during the last loading step, given their high indications. 
As pointed out in the previous paragraph, these predictions came to be confirmed after the following and last loading step of the test program, since the only debonding failures found in the beam appeared just in the location mentioned in this analysis (Figure 11), which proves that the work presented in this paper constitutes a solid experimental procedure for debonding detection.

\section{CONCLUSIONS}

Two identical RC beams with the same steel reinforcement and also the same external CFRP strengthening were tested during the experimental campaign carried out for this paper, with the purpose of applying smart sensors such as FBGs or PZTs in order to track damage evolution, thus successfully predicting debonding appearance at the FRP-concrete interface. From the direct analysis of the strain curves for each experimental test, it is not possible to conclude the presence of debonding in the strengthened beam, since FBG sensors equally respond to both kinds of damage presence in the beam: concrete cracks and interfacial debonding, taking into account that this interfacial debonding is due to a noticeable and considerably high concentration of cracks in a small region. For this reason, further treatment of these data is needed in order to obtain accurate conclusions. A model updating procedure might be used with this purpose. However, quite more precise are the conclusions obtained from the impedance-based direct analysis of the data collected by the PZT sensors, from which the location of the several debonding origins can be estimated, matching reasonably well with the real position of the debonding at the end of the test program.

\section{ACKNOWLEDGEMENTS}

The authors acknowledge the support for the work reported in this paper from the Spanish Ministry of Science and Innovation (project BIA2013-46944-C2-1-P). Financial support for the FPI research fellowship given to Enrique Sevillano and CSC research fellowship given to Rui Sun is also acknowledged.

\section{REFERENCES}

1. Sohn, H.; Farrar, C.R.; Hemez, F.M.; Shunk, D.D.; Stinemates, D.W.; Nadler, B.R.; Czarnecki, J.J. (2004) A Review of Structural Health Monitoring Literature: 1996-2001. Los Alamos National Laboratory Report, LA-13976-MS.

2. Teng, J.G.; Chen, J.F.; Smith, S.T.; Lam, L. (2002) CFRP strengthened RC structures. 1st Ed. West Sussex: John Wiley and Sons.

3. Bank, L.C. (2006) Composites for construction: structural design with CFRP materials. 1st Ed. West Sussex: John Wiley and Sons. http://dx.doi.org/10.1002/9780470121429
4. Balaguru, P.; Nanni, A.; Giancaspro, J. (2009) CFRP composites for reinforced and prestressed concrete structures. A guide to fundamentals and design for repair and retrofit. 1st Ed. Taylor and Francis, New York and London.

5. Perera, R.; Sevillano, E.; Arteaga, A.; De Diego, A. (2014) Identification of intermediate debonding damage in CFRPplated RC beams based on multi-objective particle swarm optimization without updated baseline model. Compos. Part B Eng. 62, 205-217. http://dx.doi.org/10.1016/j.compositesb. 2014.02.008

6. Attari, N.; Amziane, S.; Chemrouk, M. (2010) Flexural strengthening of concrete beams using CFRP, GCFRP and hybrid CFRP sheets. Constr. Build. Mat. 37, 746-757. http://dx.doi.org/10.1016/j.conbuildmat.2012.07.052.

7. Dong, J.; Wang, Q.; Guan, Z. (2013) Structural behaviour of RC beams with external flexural and flexural-shear strengthening by CFRP sheets. Compos. Part B Eng. 44, 604-612. http://dx.doi.org/10.1016/j.compositesb.2012.02.018.

8. El Maaddawy, T.; Soudki, K. (2008) Strengthening of reinforced concrete slabs with mechanically-anchored unbounded CFRP systems. Constr. Build. Mater. 22, 444 455. http://dx.doi.org/10.1016/j.conbuildmat.2007.07.022.

9. Yang, Z.J.; Chen, J.F.; Proverbs, D. (2003) Finite element modelling of concrete cover separation failure in CFRP plated RC beams. Constr. Build. Mater. 17 [1], 3-13. http:// dx.doi.org/10.1016/S0950-0618(02)00090-9.

10. Pesic, N.; Pilakoutas, K. (2003) Concrete beams with externally bonded flexural CFRP-reinforcement: analytical investigation of debonding failure. Compos. Part B Eng. 34 [4], 327-338. http://dx.doi.org/10.1016/S1359-8368(02) 00139-7.

11. Sebastian, W.M. (2002) Significance of midspan debonding failure in CFRP-plated concrete beams. J. Struct. Eng. 127 [7], 792-798. http://dx.doi.org/10.1061/(ASCE) 0733-9445(2001)127:7(792).

12. Rahimi, A.; Hutchinson, A. (2001) Concrete Beams Strengthened with Externally Bonded CFRP Plates. J. Compos. Constr. 5 [1], 44-56. http://dx.doi.org/10.1061/ (ASCE) 1090-0268(2001)5:1(44).

13. Yao, J.; Teng, J.G.; Lam, L. (2005) Experimental study on intermediate crack debonding in CFRP-strengthened RC flexural members. Adv. Struct. Eng. 8 [4], 365-396. http:// dx.doi.org/10.1260/136943305774353106.

14. Ascione, L.; Feo, L. (2000) Modeling of composite/concrete interface of $\mathrm{RC}$ beams strengthened with composite laminates. Compos. Part B Eng. 31 [6-7], 535-540. http:// dx.doi.org/10.1016/s1359-8368(99)00063-3.

15. Liu, S.T.; Oehlers, D.J.; Seracino, R. (2011) Study of intermediate crack debonding in adhesively plated beams. J. Compos. Constr. 11 [2], 175-183. http://dx.doi. org/10.1061/(ASCE)1090-0268(2007)11:2(175).

16. Sun, R.; Sevillano, E.; Perera, R. (2015) A discrete spectral model for intermediate crack debonding in CFRPstrengthened RC beams. Compos. Part B Eng. 69, 562-575. http://dx.doi.org/10.1016/j.compositesb.2014.10.017.

17. Chen, G.M.; Teng, J.G.; Chen, J.F. (2011) Finite-element modelling of intermediate crack debonding in CFRPplated RC beams. J. Compos. Contr. 15 [3], 339-353. http:// dx.doi.org/10.1061/(ASCE)CC.1943-5614.0000157.

18. Leo, D.J. (2007) Engineering analysis of smart material systems, John Wiley \& Sons.

19. Glisic, B.; Inaudi, D. (2007) Fibre optic methods for structural health monitoring, John Wiley and Sons. http:// dx.doi.org/10.1002/9780470517819

20. Todd, M.D.; Nichols, J.M.; Trickey, S.T. (2007) Bragg grating-based fibre optic sensors in structural health monitoring. Philos. T. Roy. Soc. A 365 [1851], 317-344. http:// dx.doi.org/10.1098/rsta.2006.1937.

21. Giurgiutiu, V. (2008) Structural Health Monitoring with Piezoelectric Wafer Active Sensors. Elsevier Inc.

22. Fritzen, C.P.; Kraemer, P. (2009) Self-diagnosis of smart structures based on dynamical properties. Mech. Syst. Signal Pr. 23 [6], 1830-1845. http://dx.doi.org/10.1016/j. ymssp.2009.01.006.

23. Sierra-Pérez, J.; Güemes, A.; Mújica, L.E.; (2013) Damage detection by using FBGs and strain field pattern 
recognition techniques. Smart Mater. Struct. 22, 02501110. http://dx.doi.org/10.1088/0964-1726/22/2/025011.

24. Zhou, Z.; Graver, T.W.; Hsu, L.; Ou, J.P. (2003) Techniques of Advanced FBG sensors: fabrication, demodulation, encapsulation and their application in the structural health monitoring of bridges. Pac. Sci. Rev. 5, 116-121.

25. Milojević, A.; Tomić, M.; Pavlović, N. (2012) Application of FBG sensors in smart railway. $X V$ International Scientific-Expert Conference on Railways, Niš, Serbia.

26. Murawski, L.; Opoka, S.; Ostachowicz, W.; Wandowski, T.; Malinowski, P. (2011) Practical application of SHM system based on FBG sensors for offshore platform. Proceedings of the 8th International Conference on Structural Dynamics, EURODYN 2011, Leuven, Belgium.

27. Takeda, N. (2008) Fiber optic sensor-based SHM technologies for aerospace applications in Japan. Proceedings of SPIE, 6933, 693302 13. http://dx.doi.org/10.1117/12. 776838 .

28. Guo, H.; Xiao, G.; Mrad, N.; Yao, J. (2011) Fiber Optic Sensors for Structural Health Monitoring of Air Platforms. Sensors, 11, 3687-3705. http://dx.doi.org/10.3390/s110403687.

29. Giurgiutiu, V. (2008) Structural Health Monitoring with Piezoelectric Wafer Active Sensors. Elsevier Inc.

30. Saafi, M.; Sayyah, T. (2001) Health monitoring of concrete structures strengthened with advanced composite materials using piezoelectric transducers. Compos. Part B Eng. 32, 333-342. http://dx.doi.org/10.1016/s1359-8368(01)00017-8.
31. Giurgiutiu, V.; Reynolds, A.; Rogers, C.A. (1999)Experimental Investigation of $\mathrm{E} / \mathrm{M}$ Impedance Health Monitoring for Spot-Welded Structural Joints. J. Intel. Mat. Syst. Str. http:// dx.doi.org/10.1106/N0J5-6UJ2-WlGV-Q8MC.

32. Giurgiutiu, V.; Harries, K.; Petrou, M.; Bost, J.; Quattlebaum, J.B. (2003) Disbond detection with piezoelectriz wafer active sensors in RC structures strengthened with CFRP composite overlays. Esarth. Eng. Eng. Vib. 2 [2]. http://dx.doi.org/10.1007/s11803-003-0005-9.

33. Liang, C.; Sun, F.P.; Rogers, C.A. (1994) Coupled electro-mechanical analysis of adaptive material systems determination of the actuator power consumption and system energy transfer. J. Intel. Mat. Syst. Str. 5, 12-20. http:// dx.doi.org/10.1177/1045389x9400500102.

34. Park, G.; Farrar, C.R.; Rutherford, A.C.; Robertson, A.C. (2006) Piezoelectric active sensor self-diagnosis using electric admittance measurements. J. Vib. Acoust. 128, 469-476. http://dx.doi.org/10.1115/1.2202157

35. Yang, Y.; Divsholli, B.S. (2010) Sub-Frequency Interval Approach in Electromechanical Impedance Technique for Concrete Structure Health Monitoring. Sensors, 10, 11644-11661. http://dx.doi.org/10.3390/s101211644.

36. Peairs, D.M.; Tarazaga, P.A.; Inman, D.J. (2006) A study on the correlation between PZT and MFC resonance peaks and adequate damage detection frequency intervals using the impedance method. International Conference on Noise \& Vibration Engineering (ISMA), Leuven, Belgium. 